\title{
The trajectory of chronic pain: Can a community-based exercise/education program soften the ride?
}

\author{
Ruth Dubin MD PhD FCFP ${ }^{1}$, Cheryl King-VanVlack BSc MSc PhD ${ }^{2}$
}

\begin{abstract}
R Dubin, C King-VanVlack. The trajectory of chronic pain: Can a community-based exercise/education program soften the ride? Pain Res Manage 2010;15(6):361-368.

The entire primary care record of six patients attending a community-based education/exercise self-management program for chronic noncancer pain (YMCA Pain Exercise/Education Program [Y-PEP]) was reviewed. Medical visits, consultations and hospital admissions were coded as related or unrelated to their pain diagnoses. Mood disruption, financial concerns, conflicts with employers/insurers, analgesic doses, medication side effects and major life events were also recorded. The 'chronic pain trajectory' resembled a roller coaster with increased health care visits at the time of initial injuries and during 'crises' (reinjury, conflict with insurers/employers, failed backto-work attempts and life events). Visits decreased when conflicts were resolved. Analgesic doses increased during 'crises' but did not fall after resolution. After attending Y-PEP, health care use fell for four of six patients and two returned to work. Primary care physicians need to recognize the functional limitations and psychosocial complications experienced by their chronic pain patients. A program such as Y-PEP may promote active selfmanagement strategies resulting in lowered health care use.
\end{abstract}

Key Words: Chronic pain trajectory; Conflict; Exercise; Health care use; Selfmanagement

\section{La trajectoire de la douleur chronique : Un programme communautaire d'exercices ou d'éducation communautaire peut-il atténuer le problème?}

Les chercheurs ont analysé le dossier de soins primaires complet de six patients qui ont participé à un programme communautaire d'autogestion de l'éducation et d'exercices pour soigner des douleurs non cancéreuses chroniques (programme d'exercices et d'éducation de la douleur du YMCA [Y-PEP]). Ils ont codé les visites médicales, les consultations et les hospitalisations comme liées ou non aux diagnostics de douleur. Ils ont également consigné les perturbations de l'humeur, les préoccupations financières, les conflits avec les employeurs et les assureurs, les doses d'analgésiques, les effets secondaires des médicaments et les grands événements de la vie. La « trajectoire de la douleur chronique » ressemblait à des montagnes russes, un plus grand nombre de visites de santé ayant lieu au moment de la blessure initiale et pendant les " crises » (nouvelles blessures, conflit avec les assureurs ou les employeurs, échecs de retour au travail et événements de la vie). Le nombre de visites diminuait une fois les conflits résolus. Les doses d'analgésiques augmentaient pendant les " crises », mais ne diminuaient pas après la résolution. Après avoir assisté à l'Y-PEP, quatre des six patients ont réduit leur utilisation des soins de santé, et deux ont repris le travail. Les médecins de premier recours doivent convenir des limites fonctionnelles et des complications psychosociales de leurs patients ayant des douleurs chroniques. Un programme comme l'Y-PEP pourrait promouvoir des stratégies de prise en charge active qui favoriseraient une moins grande utilisation des soins de santé.

chronic pain patients have revealed that those with more severe pain and greater psychosocial dysfunction have greater health care use $(4,5)$. Chronic pain leads to significant societal costs both in Canada and worldwide (6-8).

Access to pain specialists is limited in Canada. At the same time, nonspecialist physicians are poorly trained in diagnosing and treating chronic noncancer pain. This leads to multiple barriers when treating chronic pain patients including opiophobia; concerns regarding addiction, drug diversion and regulatory agencies; time constraints; and lack of knowledge regarding chronic pain pathophysiology and adjunctive treatments (9-12).

Alternative therapies for chronic pain, including exercise and self-management, have been evaluated and validated (13-16). Such nonmedical interventions can assist patients in coping with and adapting to their illnesses. As well, pain rehabilitation programs provide better functional outcomes and are more cost effective than conservative care, surgery or more invasive procedures (17).

In 2005, a multidisciplinary group of professionals in Kingston, Ontario, developed a community-based exercise long-term disability and restricted activity, and account for one-fifth of all health care use. Population-based studies on

${ }^{1}$ Kingston Family Health Team and Department of Family Medicine; ${ }^{2}$ School of Rehabilitation Therapy, Queen's University, Kingston, Ontario

Correspondence and reprints: Dr Ruth Dubin, Suite 403, 800 Princess Street, Kingston, Ontario K7L 5E4. Telephone 613-549-0464,

fax 613-549-0490, e-mail rdubin@kingston.net 
TABLE 1

Demographic characteristics of case history patients

\begin{tabular}{|c|c|c|c|c|c|c|}
\hline Patient & Age, years/sex & Pain source & $\begin{array}{l}\text { Duration of } \\
\text { pain, years }\end{array}$ & Other issues & Source of income & $\begin{array}{l}\text { Length of medical } \\
\text { record, years }\end{array}$ \\
\hline A & 50/female & Back, pelvis & 35 & Childhood abuse, substance abuse & Spouse & 7 \\
\hline $\mathrm{B}$ & 43/male & Back & 8 & War, immigration & WSIB & 18 \\
\hline $\mathrm{C}$ & 50/male & Back & 13 & PTSD, immigration & WSIB & 19 \\
\hline $\mathrm{D}$ & 45/male & Back, viral & 20 & Childhood abuse, substance abuse & ODSP & 12 \\
\hline$E$ & 32/female & Back & 6 & Childhood abuse & Spouse & 20 \\
\hline $\mathrm{F}$ & 34/male & Back & 3 & Litigation & LTD & 4 \\
\hline
\end{tabular}

LTD Long-term disability; ODSP Ontario Disabilities Support Program; PTSD Post-traumatic stress disorder; WSIB Workplace Safety and Insurance Board

and education program for adults with chronic noncancer pain (YMCA Pain Exercise/Education Program [Y-PEP]). The pilot program consisted of two $1.5 \mathrm{~h}$ sessions per week for 12 weeks in 2006. It was reduced to 10 weeks in 2007 as a result of input from the attendees and the YMCA. The education component was based on the Chronic Pain Self-management Program (Dr Sandra Lefort $[18,19]$ ) and included topics such as understanding pain, becoming a chronic pain self-manager, pacing, communication, nutrition, problem solving, dealing with emotional issues and goal setting. Each participant received Dr Lefort's Chronic Pain Self-Management Workbook $(18,19)$. In the initial phases of the program, greater time was spent on educational components, with some gentle exercise that included the Range of Motion Dance $(18,19)$. Physiotherapists and Kingston Family YMCA staff developed additional mild exercises such as walking, tai chi, pool therapy and yoga that were incorporated as the program progressed.

Participants were recruited by referral from the physicians associated with the Y-PEP planning group in 2006, and by community physicians or patient self-referral in 2007. Physicians approached patients in their practices who had not responded well to many other traditional treatments, the rationale being that individuals with severe chronic pain might receive the most benefit from such a program.

A questionnaire-based study (20) of the participants found them to be as disabled in their daily activities as end-stage renal failure patients. Increased activity was associated with decreases in pain perception, the degree to which pain interfered with their daily activities, and depression. In interviews, three themes leading to enhanced quality of life were identified - the acquisition of coping mechanisms, increased hope and social support (20).

Case histories can provide powerful descriptions of the course of an illness and bring to light factors affecting patient outcomes that were not apparent earlier. One of the authors (RD) was the primary care provider for six patients with severe chronic pain who attended Y-PEP. The purpose of the present article is to describe the pattern of health care use over time (the chronic pain trajectory) in these six chronic pain patients. We hoped to identify some factors that may have an impact on health care use and to suggest ways for health care providers to better assist their chronic pain patients.

\section{METHODS}

Individual consent was obtained from five patients involved in the 2006 Y-PEP pilot program, and a sixth patient who completed the program in 2007. As part of a larger study approved by the research ethics board of Queen's University (Kingston), these patients had previously completed questionnaires relating to their general demographics, function, mood, pain levels, degree of catastrophizing and locus of control (20).

Each patient's complete file was reviewed, tabulating the annual number of visits to the physician's office, emergency departments, after-hours clinics and consultants (eg, medical specialists, physiotherapists, psychologists and other health professionals). Visits were coded as being related or unrelated to the main chronic pain condition. Discussions during office visits about complications such as medication side effects, depression (including low mood, anxiety and sleep disruption), financial stressors, conflict with employers, insurers or lawyers, and major life events were also noted. Technological investigations (computed tomography, magnetic resonance imaging [MRI] and bone scans), which can be expensive, were also noted. A graphic time profile of patients' health care visits over time was constructed.

Patients' greatest annual analgesic use was scored as $0=$ none prescribed, 1 = acetaminophen or ibuprofen, 2 = acetaminophen with codeine or oxycodone, 3 = long-acting narcotics (less than $300 \mathrm{mg} /$ day morphine equivalent), and $4=$ long-acting narcotics $(300 \mathrm{mg} /$ day morphine equivalent or greater) or methadone.

\section{Demographic information}

\section{RESULTS}

Demographic information for these patients, including their main pain diagnosis and source of financial support, is shown in Table 1. Medical records spanned a time period ranging from four to 20 years. Back pain, most often occurring initially at work, was the major cause of chronic pain. The average length of time with chronic pain was 14 years (range three to 35 years). Significant comorbidities were present, including previous drug and alcohol abuse, childhood experiences of abuse and previous depressions that were unrelated to their chronic pain diagnosis. Two patients had immigrated to Canada due to civil war in their country of origin; one had been diagnosed with post-traumatic stress disorder. One patient lacked any history of psychiatric or social difficulties, but was involved in litigation. None of the six patients were working at the time of Y-PEP.

Initial scores from the Pain Catastrophizing Scale (21), Brief Pain Inventory (22) and Patient Health Questionnaire (23) were obtained at the first Y-PEP session. These six individuals reported moderate pain levels with average pain scores of 5.4/10 (range 2 to 7 ). The degree to which pain interfered with their lives was relatively high (mean 51/70; range 26 to 62). Most had moderate to severe depression scores (mean 12.8/27; range 9 to 21). This 


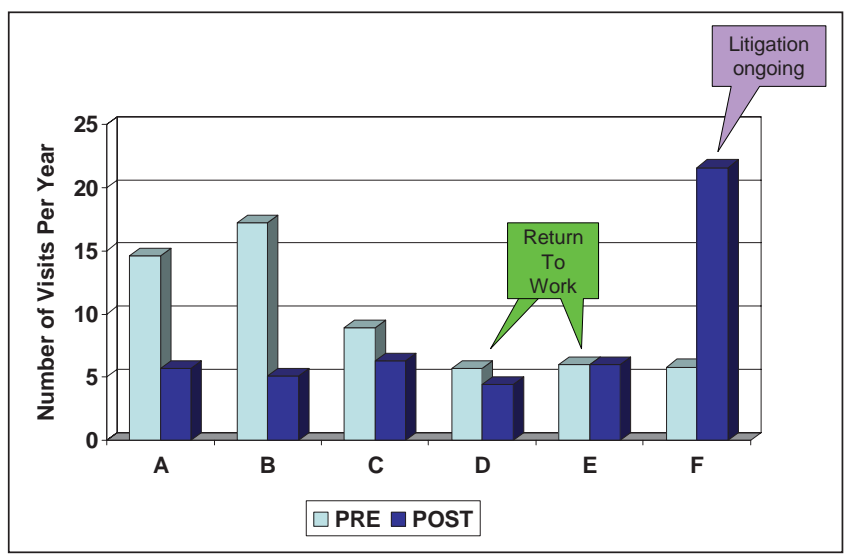

Figure 1) Annual health care visits for patients A through $F$, before (PRE) and after (POST) the YMCA Pain Exercise/Education Program based on the total visits in the 18 months preceding and following the program

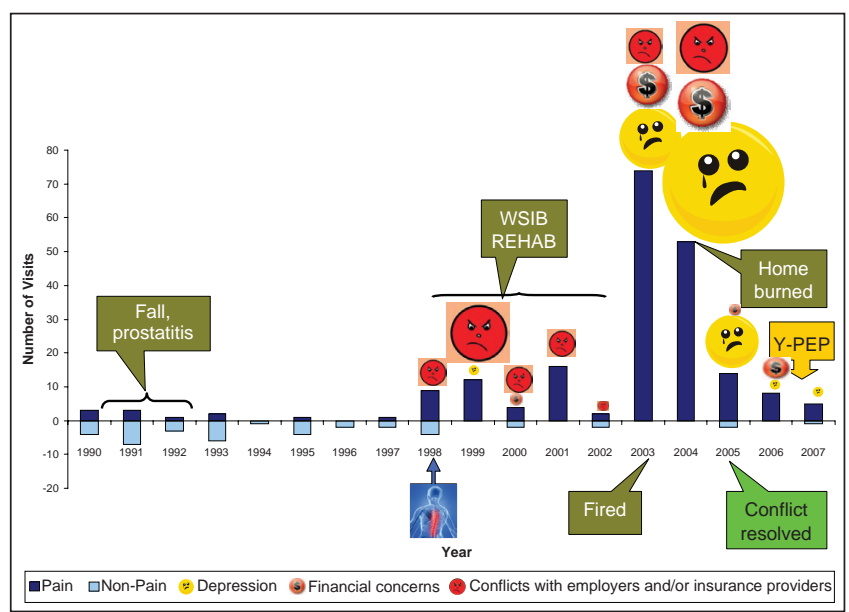

Figure 2) The pain trajectory for patient B from 1990 to 2007. This patient's number of pain visits in 2003 and 2004 was very high because the patient was receiving trigger point injections. The size of the symbols reflects the proportion of visits at which these themes were discussed. The blue 'back pain' figure indicates when the back injury occurred. Rehab Rehabilitation; WSIB Workplace Safety and Insurance Board; Y-PEP YMCA Pain Exercise/Education Program

group also tended to catastrophize about pain (mean 33/52; range 20 to 44). Their physical function/activity levels were as limited as those reported for the larger group previously described (20).

Total health care use data obtained for the 18 months before and following Y-PEP are shown in Figure 1. Substantive reductions in health care visits per annum were observed in patients $A$ and $B$, with lesser reductions in patients $C$ and $D$. Patients D and E, who had previously been unemployed for four and eight years, respectively, returned to the workforce after attending Y-PEP. Patient F, the only patient still involved in ongoing litigation, demonstrated increased health care visits following Y-PEP.

\section{Case history descriptions}

The graphic pain trajectories for the four patients $(B, C, D$ and E) with the longest medical records are shown in Figures 2

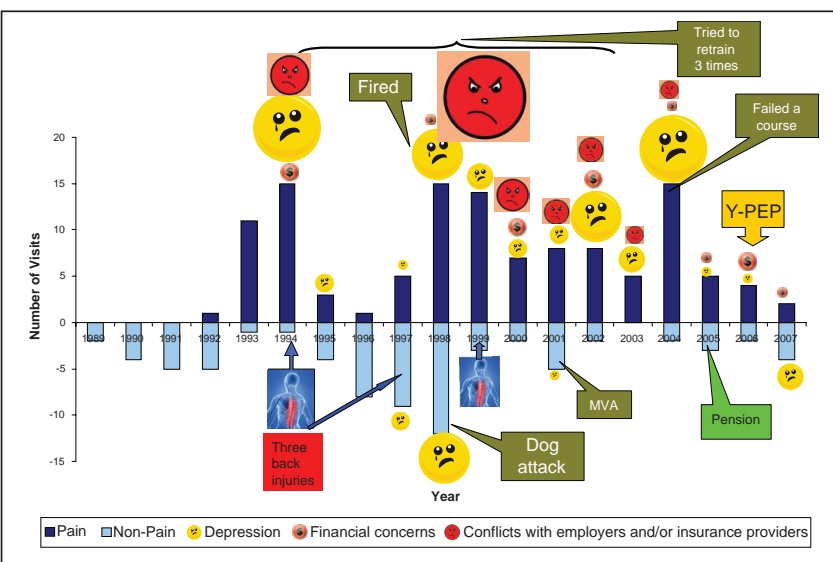

Figure 3) The pain trajectory for patient C from 1989 to 2007. This patient had three work-related back injuries and tried to retrain three times before receiving a Workplace Safety and Insurance Board pension. The size of the symbols reflects the proportion of visits at which these themes were discussed. The blue 'back pain' figures indicate when the back injuries occurred. MVA Motor vehicle accident; Y-PEP YMCA Pain Exercise/Education Program

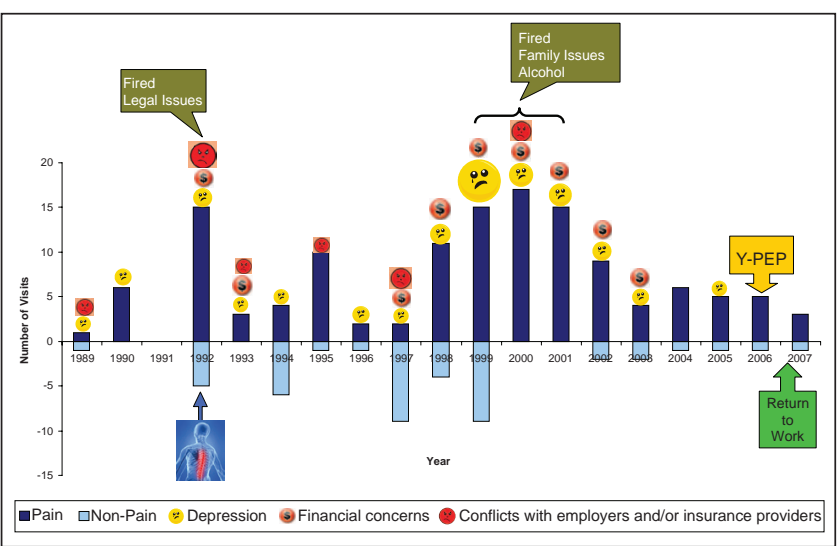

Figure 4) The pain trajectory for patient D from 1989 to 2007. The size of the symbols reflects the proportion of visits at which these themes were discussed. The blue 'back pain' figure indicates when the back injury occurred. Y-PEP YMCA Pain Exercise/Education Program

to 5. Annual pain-related visits and nonpain-related visits are plotted above and below the midline axis, respectively. Visit themes of depression, conflicts with employers, insurers and lawyers, and financial concerns are illustrated as cartoon circles above the pain visit histogram. The diameter of each circle reflects the percentage of visits annually at which these themes were discussed.

Patient B (Figure 2) immigrated to Canada from a war-torn country in 1990, and successfully advanced to a managerial position. In his early years, he suffered from mild lower back pain and prostatitis with no functional limitations. In 1998, a back injury at work led to four years of intensive rehabilitation efforts through the Workplace Safety and Insurance Board (WSIB) while he continued to work. He often missed work due to pain flare-ups and was fired in 2003. At this point, his pain visits skyrocketed and he was seen frequently for trigger point injections on the advice of a pain specialist. He became 


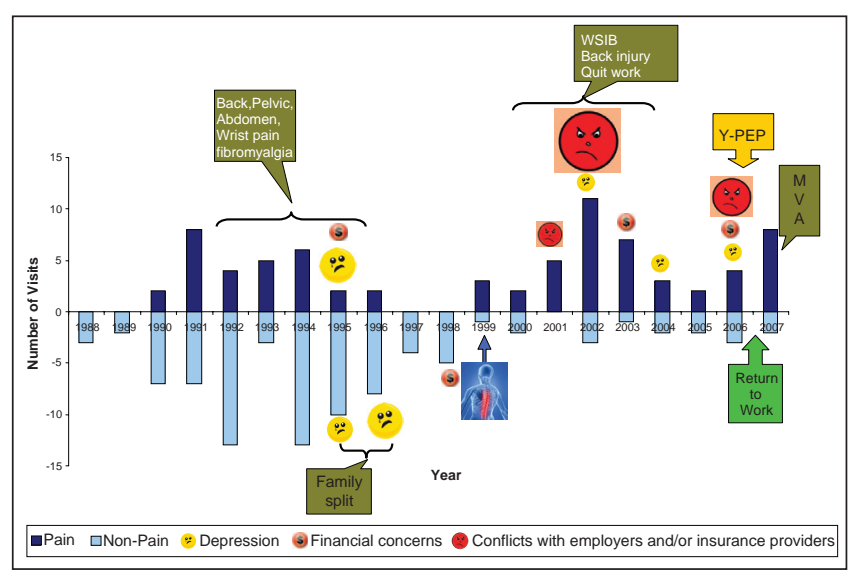

Figure 5) Pain trajectory in patient E from 1988 to 2007. After the YMCA Pain Exercise/Education Program (Y-PEP), this patient discontinued opioid analgesics and returned to full-time work. Unfortunately, shortly thereafter the patient was involved in a motor vehicle accident (MVA) and remains completely disabled at present. The size of the symbols reflects the proportion of visits at which these themes were discussed. The blue 'back pain' figure indicates when the back injury occurred. WSIB Workplace Safety and Insurance Board

severely depressed, had major financial stressors and was admitted briefly to a psychiatric ward after his home burned down in 2004. He also developed hypertension and morbid obesity. Pain visits and depression fell once his home was rebuilt, his pension was granted from WSIB and he gave up his dream of returning to work.

Patient C (Figure 3) emigrated from the same country as patient B. His very first job in a health care setting involved some patient lifting from which he suffered a back injury in 1994; rehabilitation efforts through his workplace ensued. He became severely depressed in 1997 and was admitted briefly to a psychiatric ward in 1998 after his dog attacked a neighbour causing serious injuries. Patient $\mathrm{C}$ was also diagnosed with hypertension, diabetes, noncardiac chest pain and posttraumatic stress disorder relating to events in his country of origin. He successfully retrained as an addictions counsellor, but reinjured his back at work in 1999 while attempting to catch a client who was collapsing. Again, intensive physiotherapy occurred. He had a car accident in 2001 causing further pain. In 2004, in another attempt to retrain, he failed a course at school and finally accepted a WSIB pension at which point his health care visits fell.

Patient D (Figure 4) became a patient on discharge from a psychiatric hospital in 1989, where he had been admitted for several months with severe depression. He had suffered significant childhood physical and verbal abuse, was illiterate and had substance use issues (alcohol, intravenous drugs and cocaine). His pain was a combination of ankle pain from an injury requiring multiple surgeries in 1992, abdominal pain due to hepatitis $\mathrm{C}$ and lower back pain. Interferon treatment for his hepatitis was declined by gastroenterology because of his previous depressions. His pain visits increased over several years (1998 to 2002) when he was fired from a part-time job, had major conflicts with his wife and was abusing alcohol. Patient D attained abstinence from alcohol and illicit drugs in 2003, which was associated with fewer health care visits. In late 2006, after attending Y-PEP, he returned to a part-time job (after eight years of unemployment) that he currently continues to enjoy.

Patient E (Figure 5) had been a patient since 1988 when she was a teenaged ward of the Children's Aid Society. She became a ward due to sexual abuse. In her early years, she had back, pelvic, wrist and abdominal pain and was diagnosed with fibromyalgia. She had a pregnancy in 1992, with subsequent depression when she voluntarily gave her child up for adoption. She worked full time at a manual job in which a back injury in 1999 led to rehabilitation efforts through WSIB. Eventually, she quit this job rather than 'fight' with the employer and WSIB over their return-to-work expectations. She was supported by her spouse and did occasional work painting houses. After completing Y-PEP, she remained a member of the YMCA, reduced her long-acting opioid analgesic dosage and accepted a fulltime job at a call centre. She also decided to leave her spouse because of verbal abuse. Unfortunately, she was involved in a minor car accident in December 2007 at which point her back pain flared, she had to leave work and, for financial reasons, she had to move back in with her spouse. She is embroiled in legal issues regarding the accident at this time, is taking higher doses of opioid analgesics and remains completely disabled.

Patient A (trajectory not graphed) had been a patient for seven years. She had a 30-year history of chronic back and pelvic pain (due to endometriosis) as well as chronic depression. She was sexually, physically and verbally abused as a child. She had a history of substance abuse and still smokes marijuana daily. Since attending Y-PEP, she has been less depressed and her physician visits have fallen to only those required for regular prescription renewals and preventive care.

Patient $F$ was referred following a car accident that left him completely disabled and incapable of returning to his job as a truck driver. He had been briefly off work several years previously due to a shoulder injury from which he was completely rehabilitated. He had no previous psychosocial problems, but did have well-controlled hypertension. During and after Y-PEP, he remained disabled, with severe depression, and had multiple visits for uncontrolled pain. Litigation regarding the accident was not settled until late 2008, after which only one office visit occurred over a period of six weeks. Unfortunately, two days after his legal settlement, he suffered a minor ischemic stroke resulting in hospital admission, but his neurological deficits have resolved. He is no longer taking opiates, and he was only seen in the office two times in 2009.

\section{Chronic pain trajectory}

The chronic pain trajectory was like a roller coaster with surges in medical usage at the time of the injury and later during 'crises' when pressure from insurers, failed back-to-work attempts or other personal troubles occurred. At the time of the initial injury, there were consultations to physiotherapists and specialists including physiatrists, orthopedic surgeons and others, as well as computed tomography or MRI scans. Early in the pain trajectory, patients and their primary care physicians invested energy into making a diagnosis and achieving recovery. All six patients had typical findings (spinal stenosis, disc herniations and compression fractures) on radiological examinations that correlated to some degree with their symptoms, but none were considered to be surgical candidates. 

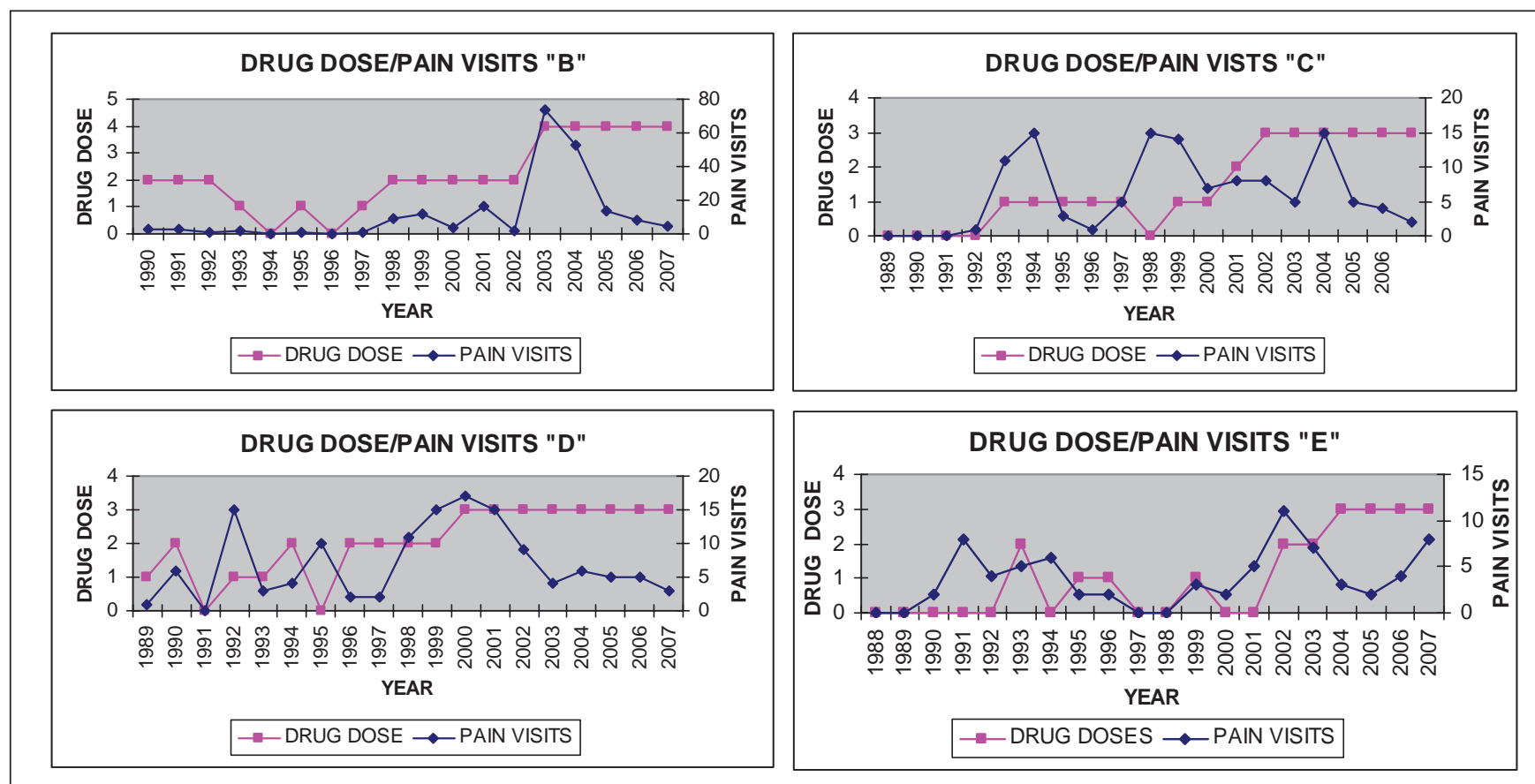

Figure 6) Drug doses (pink) and patient visits over time (blue) shown for the four patients with the longest medical records (patients B, C, $D$ and E). Drug doses were scored as $0=$ none, $1=$ ibuprofen or acetaminophen, $2=$ acetaminophen plus codeine or oxycodone, $3=$ long-acting narcotics (less than $300 \mathrm{mg} /$ day morphine equivalent) and 4 = long-acting narcotics (300 mg/day morphine equivalent or greater)

Visits, consultations and scans also tended to increase again later during 'crises' related to return-to-work attempts, conflicts with insurers and employers, financial stresses and depression. Pain in and of itself was not the only theme during these encounters; socioeconomic and employment problems, as well as significant mood disruption occurred. All six patients received antidepressant medications at some time during their illness, and two were admitted for psychiatric care during 'crises'. Personal events unrelated to the pain condition also occurred (patient B - home burned down, patient $\mathrm{C}-\operatorname{dog}$ attacked a neighbour and patient $\mathrm{E}$ - family broke up). These were often associated with increases in pain-related visits.

The occupational, insurance, financial and mood themes did not recede from patients' visits until socioeconomic and occupational or insurance conflicts were resolved. In two selfdescribed 'workaholics' (patients B and C, Figures 2 and 3), this occurred when return-to-work efforts were abandoned and a WSIB pension was granted. These two individuals placed great value on being employed, made the most return-to-work or retraining attempts and, in retrospect, had the most physician visits. Patient E (Figure 5) quit work in 2002 rather than comply with WSIB return-to-work pressure and was supported by her spouse.

\section{Patient function after attending Y-PEP}

Patient $E$ appeared to be the person best able to profit from the coping mechanisms learned at Y-PEP until her car accident in late 2007. After attending Y-PEP, she had the greatest functional improvement, a sustained fall in the degree to which pain interfered with her life, the lowest pain catastrophizing scores and the greatest sustained fall in her depression score. Patients D and E, who returned to work after attending Y-PEP, had the lowest number of health care visits before attending
Y-PEP and the least change afterward (Figure 1). Their depression scores were among the lowest, consistent with the clinical impression that they were the least distressed patients in this group. They demonstrated high internal locus of control, possibly indicating that these two felt more in control of their lives. With the exception of patient $\mathrm{F}$, who was still involved in litigation until late 2008, and patient $\mathrm{E}$, who had a car accident in late 2007, the other Y-PEP participants maintained their reduced health care use after Y-PEP.

\section{Drug doses and side effects}

In general, analgesic drug doses increased at times when painrelated visits increased, but did not fall afterward (Figure 6). Significant analgesic dose reduction was not observed after attending Y-PEP. The number of medication side effects (eg, constipation and nausea) increased along with increasing drug doses and could have contributed to the patients' subjective feelings of ill health (Figure 7). However, while side effects were part of these patients' medical visits, they were rarely the main reason for seeing the doctor. Continued use of opioids did not prevent patients from returning to work or reducing their health care use after attending Y-PEP. Two patients (A and D) had histories of substance abuse, but neither were actively abusing substances by the time of Y-PEP, with the exception of patient $\mathrm{A}$, who still smoked marijuana daily for pain relief. None of the six patients displayed aberrant opioid analgesic-related behaviours and all 'passed' regular urine drug screens.

\section{DISCUSSION}

The present case study review of six patients, when interpreted within the context of the related literature, leads to the observations listed below. 


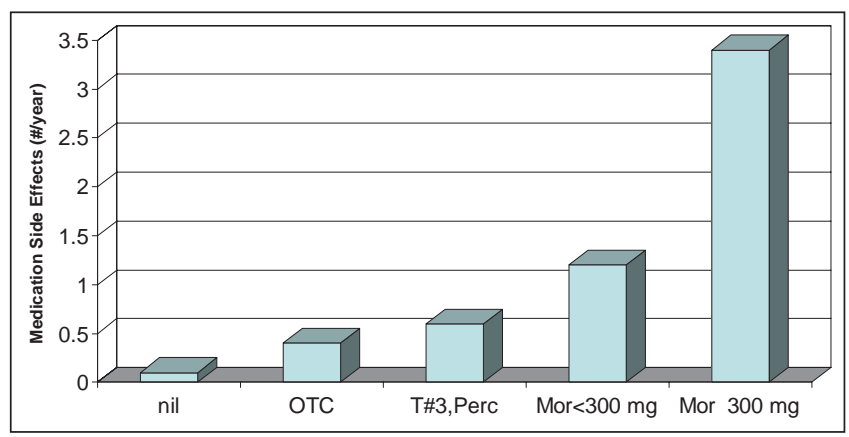

Figure 7) The number of medication side effects reported per year based on the type of medication and dosage. Mor $<300 \mathrm{mg}$ Morphine equivalent of less than $300 \mathrm{mg} /$ day; Mor $\geq 300 \mathrm{mg}$ Morphine equivalent of $300 \mathrm{mg} /$ day or greater, or methadone; OTC Over-thecounter analgesics such as ibuprofen or acetaminophen; nil No analgesics recommended; T\#3,Perc Acetaminophen with codeine (30 $\mathrm{mg}$ ) or acetaminophen with oxycodone $(5 \mathrm{mg}$ )

\section{'Pain' visits are not just about pain}

Visits about 'pain' also involve occupational, financial and psychosocial stress, and insurer conflict. However, physicians, being trained in the medical model, may focus on the 'chief complaint' of pain and ignore the underlying life stressors that could be driving the 'presenting symptom'. Doctors may react to the patients' distress by ordering more tests and consultations, and prescribing even stronger doses of narcotic analgesics, with an inevitable increase in side effects. Failure to assist patients in resolving their psychosocial conflicts may perpetuate their suffering and prolong their difficulties with day-to-day functioning. Patients may not volunteer that they are litigating, and practitioner failure to ask specifically may leave them blinded to a major source of patient stress. Indeed, pain alone may not be the most important limiting symptom. Sullivan et al (24) have shown that return-to-work interventions succeed without a decrease in pain when other psychosocial factors are controlled, thus emphasizing the importance of multiple biopsychosocial factors in chronic pain treatment.

\section{Stress may increase patients' pain}

Patients with compensation and litigation issues are known to be more functionally impaired and suffer more pain and depression $(25,26)$. Workers identified by the WSIB in Ontario as having management problems had a higher prevalence of nondermatomal sensory loss, which has been associated with altered functional MRI brain activation patterns (27). Chronic pain is an inflammatory state (28). It is conceivable that the stress of dealing with insurers and lawyers could increase pain perceptions through inflammatory mechanisms leading to 'maladaptive' neuroplasticity. Insurers may be contributing to patients' levels of stress and disability by adopting a confrontational approach, pushing for a return to work and by questioning patients' true functional restrictions.

\section{Why patients need to understand their condition}

'Mechanical back pain' was the most frequently charted diagnosis for these patients. This nonspecific term may have created patient anxiety. Without a clear diagnosis, patients quite rationally worry that they have 'something seriously wrong', which may lead to more visits and attempts to find an answer. Inflammatory bowel sufferers with more disease-related anxiety are known to use health care more frequently (29). Understanding the nature of chronic pain, as taught during Y-PEP, may have helped to reduce patients' worries and their health care visits.

\section{The value of self-management and Y-PEP}

Community-based self-management programs can be relatively inexpensive and accessible. The self-management portion of Y-PEP was evaluated in a randomized trial with a wait-list control by Lefort (19). She found significant improvements in mental health composite score (vitality, social and emotional functioning, and mental health) and resourcefulness, and trends of improvement in disability, psychosocial adjustment to illness and life satisfaction. Similarly, in interviews after Y-PEP, participants reported that the program improved their coping mechanisms, hope and social support (20). In addition, reductions in depression were associated with increases in physical function and reductions in the degree to which pain interfered with their lives. Enhanced understanding of their pain and acceptance of their chronic condition may have led to reduced pain interference, disability and health care use (30). Y-PEP may have promoted more active coping mechanisms such as exercise, meditation and social interaction, which are more effective than passive strategies in reducing pain-related disability and health care visits (5). Self-management programs are known to increase self-efficacy, ie, an individual's belief in their competence or ability to manage their condition (15).

\section{Lessons learned}

The biomedical approach alone is insufficient to optimally control persistent pain, and prevent or reduce pain-related disability. Psychosocial factors that predict a poor prognosis with respect to return to work include catastrophizing, worse perceived pain and functional disability, fear of pain, poor problem solving, low expectations and lack of confidence, job stress, lack of coworker support for modified duties and lack of autonomy (24). Patients may feel that the current insurance model removes their autonomy. Insurers may increase stress by withholding financial support and pressuring patients to return to work when they do not feel ready. The degree to which pain interferes with work, family and social life, and depression are among the predictors of a future development of chronic pain (3).

These psychosocial complications are the 'flags' that primary care providers should look for, rather than the less common physical pathologies that are usually ruled out early in the diagnostic process. Training of family physicians to recognize chronic noncancer pain as a condition in its own right might allow them to better educate their patients, leading to enhanced acceptance and understanding of their condition. Facilitating the resolution of patients' insurance, occupational, financial and mood issues should also be an important component of the primary care plan.

Mailis-Gagnon et al (31) recently described 15 behavioural and physical findings in older patients referred to a tertiary pain clinic that may relate to pain augmentation and perpetuation, and that illustrate the complexity of the pain/behaviour 
interface. Family physicians have the advantage of knowing their patients before misfortune befalls them, and can learn to recognize when their previously 'normal' patients begin to exhibit psychosocial 'yellow flags' (32). All six patients in the present case study had behaved quite normally within the limits of their personalities and previous life experiences before their injuries.

While the phrase 'chronic pain trajectory' has been previously used $(2,33)$, the present study is the first to graphically depict the nature of this journey over several decades. Understanding a patient's current position on the chronic pain trajectory may allow care providers to intervene more appropriately by exploring psychosocial issues with patients whose visits suddenly increase. At the same time, it must be recognized that certain interventions may not be appropriate at certain points on the trajectory. For example, a self-management intervention such as Y-PEP may not be effective in patients who are in the midst of crises or involved in litigation.

Health care professionals are perceived as powerful by their patients. Their efforts should extend beyond 'usual' medical care to counteract the isolation, disempowerment and demoralization experienced by patients with chronic pain (33). Family practice care that is characterized by listening, understanding and shared management is the most important factor in reducing global disability in patients with occupational injuries (34). The chronic pain trajectory is a useful construct that can be used to enhance primary care of this condition.

\section{REFERENCES}

1. Valery P. Historical fact [1932]. In: The Outlook for Intelligence. New York: Harper Torchbooks, The Bollingen Library, 1962.

2. Richardson JC, Ong BN, Sim J. Remaking the future: Contemplating a life with chronic widespread pain. Chronic Illn 2006;2:206-18

3. Von Korff M, Dunn KM. Chronic pain reconsidered. Pain 2008;138:267-76.

4. Von Korff M, Lin EHB, Fenton JJ, Saunders K. Frequency and priority of pain patients' health care use. Clin J Pain 2007;23:400-8.

5. Blyth FM, March LM, Brnabic AJM, Cousins MJ. Chronic pain and frequent use of health care. Pain 2004;111:51-8.

6. Badkey EM, Rasooly I, Webster GK. Relative importance of musculoskeletal disorders as a cause of chronic health problems, disability and health care utilization: Findings from the 1990 Ontario Health Survey. J Rheumatol 1994;21:505-14.

7. Rapoport J, Jacobs P, Bell NR, Klarenbach S. Refining the measurement of the economic burden of chronic diseases in Canada. Chronic Dis Can 2004;25:3-21.

8. Guerriere DN, Zagorski B, Stafford-Coyte E, Choiniere M. Private and public costs of chronic pain in adults, economic analysis within the STOPPAIN project. Pain Res Manage 2008;13:114. (Abst)

9. Morley-Forster PK. Primary care for chronic pain sufferers. Can Fam Phys 2005;51:1073. (Lett)

10. Morley-Forster PK, Clark AJ, Speechley M, Moulin DE. Attitudes toward opioid use for chronic pain: A Canadian physician survey. Pain Res Manage 2003;8:189-94.

11. Schram K, Kohn W. Chronic pain program in a primary care setting. Pract Pain Manage 2007;7:39-45.

12. Watt-Watson J, McGillion M, Hunter J, et al. A survey of prelicensure pain curricula in health science faculties in Canadian Universities. Pain Res Manage 2008:13:151. (Abst)

13. Hayden JA, van Tulder MW, Malmivaara A, Koes BW. Exercise therapy for treatment of non-specific low back pain. Cochrane Database Syst Rev 2005;(3):CD000335.

14. Mior S. Exercise in the treatment of chronic pain. Clin J Pain 2001;17(Suppl):77-85.

\section{Limitations}

A case-study approach can provide 'rich' data from a small number of participants; however, this may be at the cost of the extent to which the information can be generalized to the chronic pain population at large. What can be said is that the findings from these six individuals with severe chronic pain are typical of those seen on a regular basis in one physician's practice. Five of the participants' major conflicts were behind them when they took part in Y-PEP; it remains to be seen whether this intervention would have been beneficial if it had been available earlier. Health care use might have fallen even without Y-PEP, although the fact that two participants returned to work seems remarkable after such a prolonged time out of the work force. Although no 'control' patients were included in the study, a chart review of two other long-term chronic pain patients who were offered but declined Y-PEP revealed no visit reductions over the same time frame. Other family physicians' approaches to managing their chronic pain patients may produce quite different pain trajectories.

ACKNOWLEDGEMENTS: Honoraria and donations from Purdue, sanofi-aventis, Valeant and Novartis supported the pilot program of Y-PEP and presentations by rehabilitation students at professional meetings. The authors gratefully acknowledge the Kingston Family YMCA, Tarey Gillard (YMCA trainer and Y-PEP leader) and the Y-PEP participants themselves.
15. Foster G, Taylor SJ, Ramsay J, Griffiths CJ. Self-management education by lay leaders for people with chronic conditions. Cochrane Database Syst Rev 2007;(4):CD005108.

16. Lorig K, Holman H. Arthritis self-management studies: A twelve year review. Health Educ Quart 1993;20:7-28

17. Turk DC. Clinical effectiveness and cost-effectiveness of treatments for patients with chronic pain. Clin J Pain 2002;18:355-65.

18. LeFort S, Gray-Donald K, Rowat M, Jeans M. Randomized controlled trial of a community-based psychoeducation program for the self-management of chronic pain. Pain 1998;74:297-306.

19. Lefort S. Self-management of chronic non-cancer pain: Results of two randomized controlled trials. Pain Res Manage 2008;13:124. (Abst)

20. King-VanVlack C, Di Rienzo G, Kinlin M, et al. Education and exercise program for chronic pain patients. Pract Pain Manag 2007;7:17-27.

21. Sullivan MJL, Bishop SR. The Pain Catastrophizing Scale: Development and validation. Psychol Assess 1995;7:524-32.

22. Clelland CA, Ryan KM. Pain assessment: Global use of the Brief Pain Inventory. Ann Acad Med Singapore 1994;23:129-38.

23. Spitzer RL, Broenke K, Willians JBW. Validation and utility of a self-report version of PRIME-MD: The PHQ Primary Care Study. JAMA 1999;282:1737-44.

24. Sullivan MJL, Feuerstein M, Gatchel R, Linton SJ, Pransky G. Integrating psychosocial and behavioral interventions to achieve optimal rehabilitation outcomes. J Occup Rehab 2005; 15:475-89.

25. Landers MR, Cheung W, Miller D, et al. Workers' compensation and litigation status influence the functional outcome of patients with neck pain. Clin J Pain 2007;23:676-82.

26. Suter PB. Employment and litigation: Improved by work, assisted by verdict. Pain 2001;100:249-57.

27. Arvantaj A, Mitrovish B, Lakha SF, Mailis N, Mailis-Gagnon A. Characteristics of injured chronic pain workers identified by workers safety and insurance board (WSIB) staff as management problems. Pain Res Manage 2008;13:31. (Abst) 
28. DeLeo JA, Yesierski RP. The role of neuroinflammation and neuroimmune activation in persistent pain. Pain 2001;90:1-6.

29. Graff LA, Walker J, Lix L, et al. Do pain anxiety and pain catastrophizing change with disease activity. Pain Res Manage 2008;13:121. (Abst)

30. LaChapelle D, Lavoie S, Boudreau A. The meaning and process of pain acceptance. Perceptions of women living with arthritis and fibromyalgia. Pain Res Manage 2008;13:201-10.

31. Mailis-Gagnon A, Nicholson K, Yegneswaran B, Zurowski M. Pain characteristics of adults 65 years of age and older referred to a tertiary care pain clinic. Pain Res Manage 2008;3:389-94.

32. Kendall NAS, Linton SJ, Main C. Psychosocial yellow flags for acute low back pain: 'Yellow flags' as an analogue to 'red flags'. Eur J Pain 1998:2:87-9.

33. Skuladottir H, Halldorsdottir S. Women in chronic pain: Sense of control and encounters with health professionals. Qual Health Res 2008;18:891-901.

34. Russell G. The family practice care of patients with occupational injuries. Unpublished doctoral dissertation, University of Western Australia, 2005. 


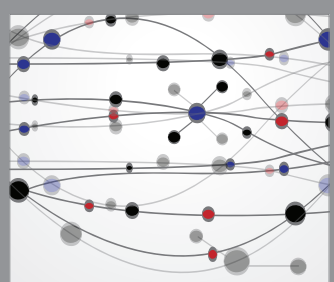

The Scientific World Journal
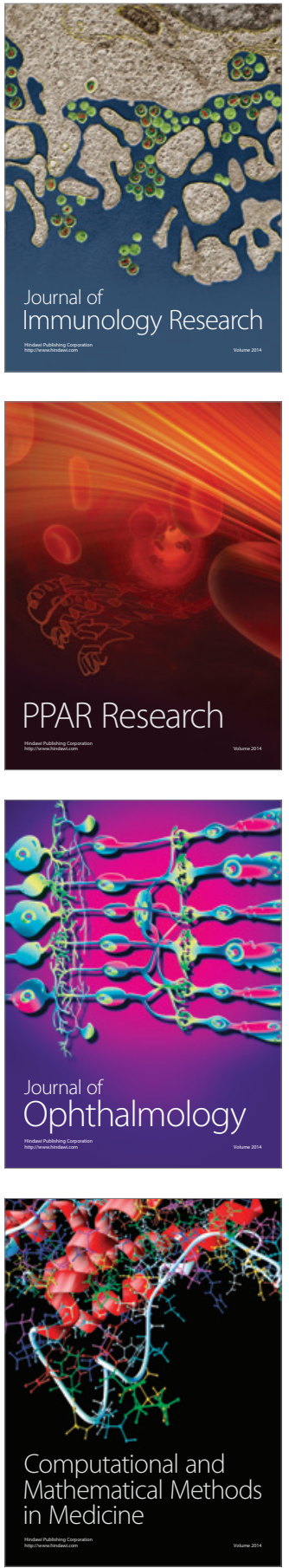

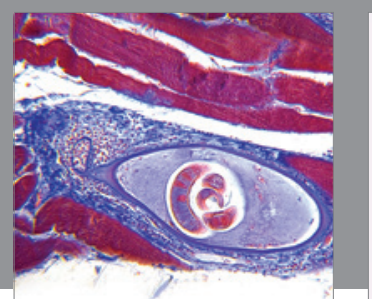

Gastroenterology Research and Practice

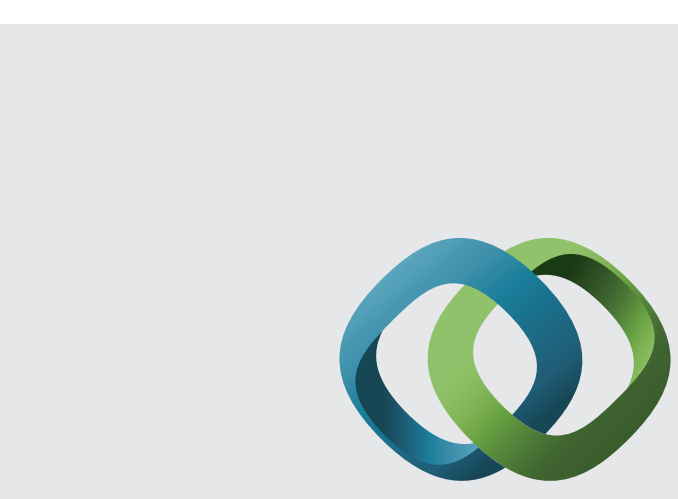

\section{Hindawi}

Submit your manuscripts at

http://www.hindawi.com
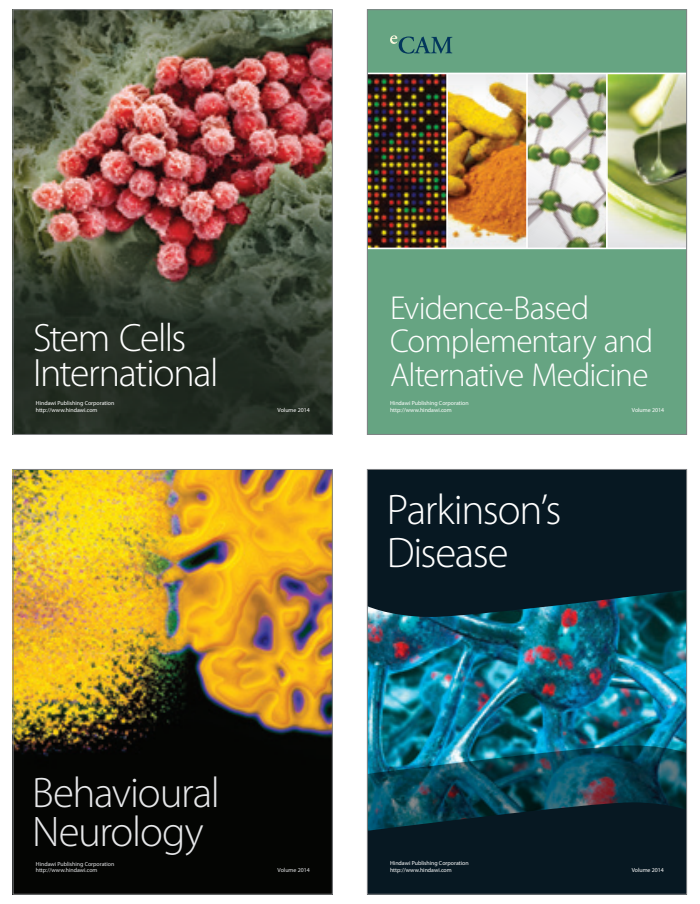
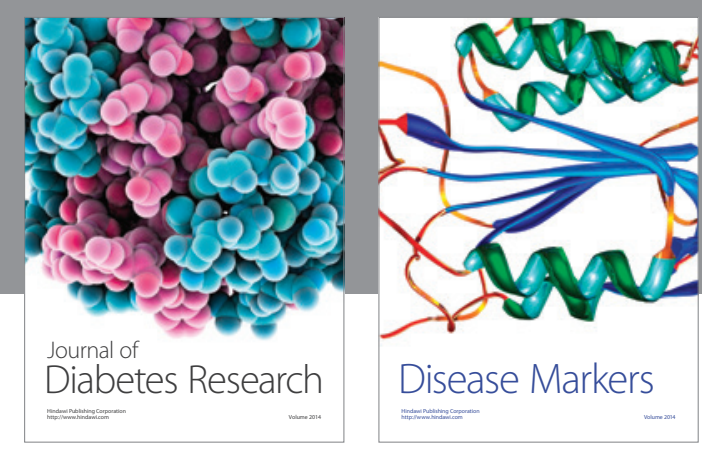

Disease Markers
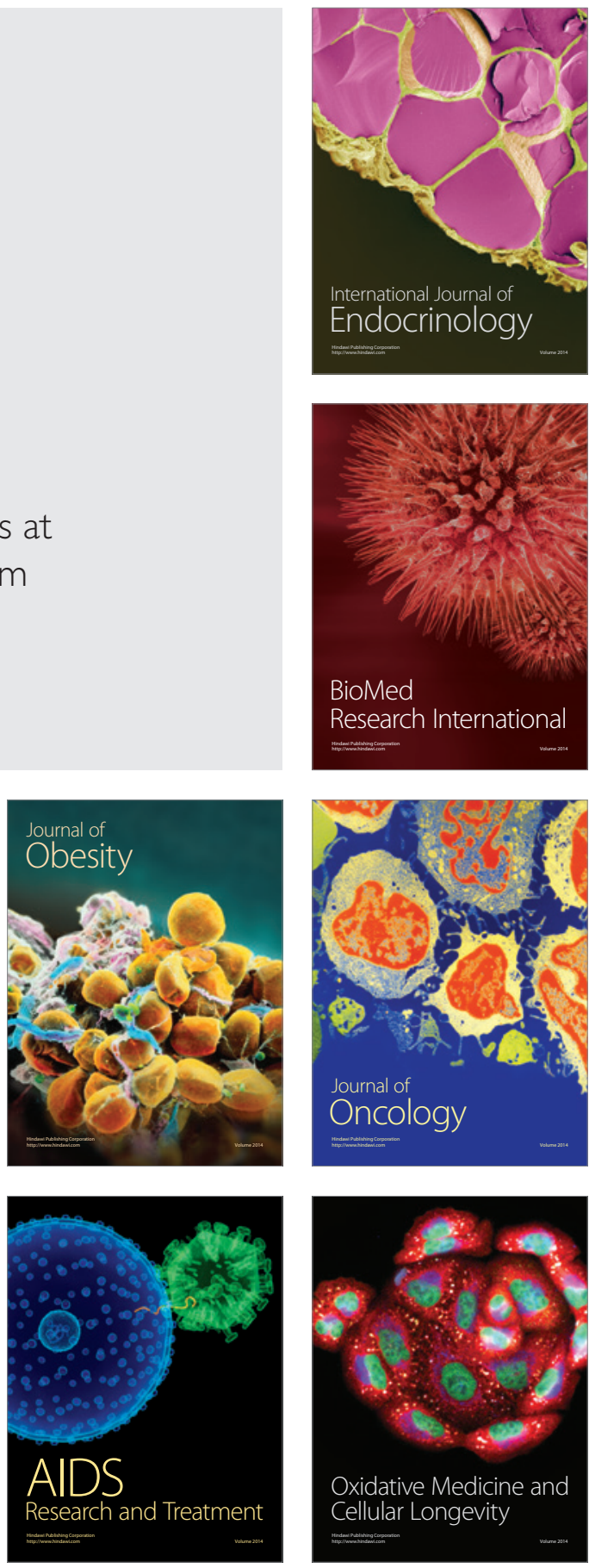